\title{
Relationship of Substance P with the Degree of Atopic Dermatitis Severity
}

\author{
Deryne Anggia Paramita (D) \\ Khairina Nasution \\ Nova Zairina Lubis \\ Department of Dermatology and \\ Venereology, Faculty of Medicine, \\ Universitas of Sumatera Utara, Sumatera \\ Utara, 20155, Indonesia
}

Correspondence: Deryne Anggia Paramita

Email deryne.anggia@usu.ac.id
Introduction: Atopic dermatitis (AD) is a chronic inflammatory skin disease that starts during childhood with a varied course. Itching or incessant itching in severe cases, sleep disturbance, and infection-prone skin are the typical symptoms of this disease. Substance $\mathrm{P}$ is postulated to have an important role in AD. Increasing levels of substance P in AD induce the release of IFN- $\gamma$, IL-4, tumor necrosis factor- $\alpha$ (TNF- $\alpha$ ), and IL-10 from peripheral blood mononuclear leukocytes, inducing an itching response.

Methods: This study is a cross-sectional study that aims to analyze the relationship between serum substance P levels and AD severity in children using Score of AD (SCORAD), and to determine the mean serum substance $P$ levels and severity of $A D$ in patients with $A D$. This study also aims to find out the correlation of substance P levels with the SCORAD values.

Results: Forty-six children (29 males; 17 females) with a mean age of 10.35 years (standard deviation $(\mathrm{SD})=4.01)$ were diagnosed with $\mathrm{AD}$. The SCORAD index assessment was conducted to analyze $\mathrm{AD}$ (mean value, 23.15; $\mathrm{SD}=9.42$ ), and mild $\mathrm{AD}$ obtained the highest degree. The level of substance $\mathrm{P}$ was also examined (mean value, 300.88; SD = 127.55).

Discussion: This study did not find a significant relationship between substance P levels and $\mathrm{AD}$ severity ( $\mathrm{p}$-value $=0.880$ ), and there was no significant correlation between substance $P$ levels and SCORAD values ( $\mathrm{p}$-value $=0.233 ; \mathrm{r}=-0.179$ ). The limitations of this study include a small number of cases, no control group, and we only found two cases of severe $\mathrm{AD}$. To generalize the results, further studies with wide range population and $\mathrm{AD}$ severity might be done in the future.

Keywords: atopic dermatitis, SCORAD, substance P, pruritus

\section{Introduction}

Atopic dermatitis (AD) is a chronic inflammatory skin disease that begins during childhood with a varied course. The typical symptoms of this disease are itching, sleep disturbance, skin excoriation, and infection-prone skin. ${ }^{1}$

$\mathrm{AD}$ is a major health problem worldwide with a prevalence of $15-30 \%$ in children and $2-10 \%$ in adults. The International Study of Asthma and Allergies in Childhood (ISSAC) found that the morbidity rate reached 20\% in Asian countries such as South Korea, Taiwan, and Japan. In developing countries, AD is estimated to be prevalent in 10-20\% of children, $60 \%$ of which persists in adulthood. ${ }^{2}$ In Indonesia, according to the Indonesian Pediatric Dermatology Study Group (KSDAI), the prevalence rate of AD cases reaches around 23.6\%, where $\mathrm{AD}$ ranked first in the top 10 skin diseases in children. ${ }^{3}$

The pathogenesis of AD remains not fully understood. It is believed that there is a complex mechanism by which the interaction between genetics, skin barrier 
dysfunction, and immunology occurs. ${ }^{4}$ Skin neuropeptides, particularly substance $\mathrm{P}$, contribute to the pathogenesis of various skin diseases, one of which is $\mathrm{AD}$. Substance $\mathrm{P}$ promotes the production of nerve growth factors from keratinocytes and the release of histamine, leukotriene, or tumor necrosis factor (TNF) from mast cells, causing the growth of sensory nerve fibers and augmentation of skin inflammation. Therefore, substance $\mathrm{P}$ is currently considered as one of the key pruritogenic factors in $\mathrm{AD} .^{5}$

The major substance $\mathrm{P}$ receptor on skin mast cells is Mas-related G protein-coupled receptor-X2 (MRGPRX2). ${ }^{6}$ Substance $\mathrm{P}$ is synthesized and released from mast cells, monocytes, and eosinophils in the skin. Substance $\mathrm{P}$, along with IL-17A, appears to be significantly elevated in the plasma of patients with $\mathrm{AD}{ }^{7}$ The components of the skin microbiome can stimulate host defense peptide production in keratinocytes, of which $\beta$-defensin and cathelicidin induce MC degranulation via MRGPRX2 and also the changes in MRGPRX2 itself or elements upstream or downstream thereof (transcription factors, signaling components) may predispose to $\mathrm{AD}$ development. ${ }^{6}$ Recent studies have also shown that substance $\mathrm{P}$ also induces the expression of endothelial cell attachment molecules such as P-selectin to a limited extent. The expression of high levels of P-selectin in the dermal vessels in skin lesions has been observed in urticaria and $\mathrm{AD}{ }^{8}$

This study aims to analyze the relationship between serum substance $\mathrm{P}$ levels and the severity of AD in children, determine the mean serum substance $P$ levels in patients with $\mathrm{AD}$, and determine the degree of severity of $\mathrm{AD}$ in patients with $\mathrm{AD}$, as well as determine the relationship between substance $P$ levels and the degree of $\mathrm{AD}$ severity and the correlation of substance P levels with the Score of Atopic Dermatitis (SCORAD) values.

\section{Methods}

This research is a cross-sectional study and was conducted at the Polyclinic of Dermatology and Venereology, Sumatera Utara University Hospital. Blood samples were examined at Prodia Laboratory in Medan. This study is done from February to November 2020, with the approval from Health Research Ethical Committee Faculty of Medicine Universitas Sumatera Utara Number 92/KEP/ USU/2020.

The subjects of this study were female and male patients with $\mathrm{AD}$ diagnosed based on Hanifin and Rajka's criteria and parent or legal guardian provided informed consent for those who were willing to take part in the study. Subjects will be excluded if their parents/ guardians cannot answer the questions given and are suspected of having skin diseases or other systemic diseases. This study was conducted in accordance with the Declaration of Helsinki. Forty-six children with AD were identified and then evaluated for the degree of severity using the SCORAD index.

Blood samples were then taken to check substance $P$ levels using the substance P ELISA kit from the R\&D Systems catalogs. Then, reagents, working standards, and samples were prepared. The excess microplate strip from the plate frame was removed, then returned to the foil pouch containing the desiccant pack, and reinstalled. Diluent RD5-45 Calibrator $(100 \mu \mathrm{L})$ was then added to the nonspecific binding (NSB) well. This is followed by the addition of Diluent Calibrator RD5-45 $(50 \mu \mathrm{L})$ to the standard zero well (B0); then, $50 \mu \mathrm{L}$ of standard, control, or sample were added to the remaining wells. Plate layouts were provided to record the standards and samples tested.

This procedure was continued by adding $50 \mu \mathrm{L}$ of primary antibody solution to each well (excluding NSB well). All wells, except the NSB well, turned blue. Then, $50 \mu \mathrm{L}$ of substance $\mathrm{P}$ conjugate was added to each well. All wells, except NSB well, now turned purple. Wells were then covered with the provided adhesive strip. Samples were incubated for 3 hours at room temperature on a horizontal orbital microplate shaker (orbit, $0.12^{\prime \prime}$ ) adjusted at $500 \pm 50 \mathrm{rpm}$.

Each well was then aspirated and washed four times. Each well was washed by filling each well with a wash buffer $(400 \mu \mathrm{L})$ using a spray bottle, dispenser manifold, or auto washer. Fluid discharge at every step is essential for good performance. After the fourth wash, the remaining buffer was removed by vacuuming or pouring. The plate was then turned over and cleaned using a clean paper towel. Then, $200 \mu \mathrm{L}$ of substrate solution was added to each well. Samples were incubated for 30 minutes at room temperature on a table and protected from mild. Stop solution $(50 \mu \mathrm{L})$ was then added to each well.

The optical density of each well was determined within 30 minutes using a microplate reader set at $450 \mathrm{~nm}$. If wavelength correction is available, it should be set to 540 or $570 \mathrm{~nm}$. If wavelength correction is unavailable, the reading should be reduced at 540 or $570 \mathrm{~nm}$ from $450 \mathrm{~nm}$. This reduction will correct for optical imperfections in the plate. Readings directly made at $450 \mathrm{~nm}$ without correction may be higher and less accurate. Then, the results will be presented in units of $\mathrm{pg} / \mathrm{mL}$. 
Data on the distribution of sex and the degree of severity of patients with $\mathrm{AD}$ were presented in the form of a descriptive table. Data on the distribution of patients with $\mathrm{AD}$ were reported as means (median \pm standard deviation (SD)). The results of the SCORAD index assessment and the measurement of substance $\mathrm{P}$ levels were reported as mean values (median $\pm \mathrm{SD}$ ). The relationship of substance P levels with the degree of AD severity was determined using the Kruskal-Wallis test, and the relationship between substance P levels and SCORAD was tested using the Spearman correlation.

\section{Result}

A total of 46 children with AD were enrolled in this study. They visited the Polyclinic of Dermatology and Venereology Universitas Sumatera Utara Hospital, Medan, from February 2020 to November 2020. The inclusion and exclusion criteria were met. There were 29 male subjects $(63 \%)$ and 17 female subjects (37\%) (Table 1).

The mean age of subjects with $\mathrm{AD}$ who were enrolled in the study was 10.35 years ( $\mathrm{SD}=4.01)$, with the youngest being 1 year old and the oldest being 17 years old (Table 2). Table 3 presents the results of the SCORAD assessment of all research subjects. The mean SCORAD was 23.15 ( $\mathrm{SD}=9.42$ ), with the lowest SCORAD being 10.8 and the highest being 59.6.

The results of the SCORAD index categorization indicated that majority of study subjects experienced AD with

Table I The Frequency Distribution of Gender of the Research Subjects

\begin{tabular}{|l|c|c|}
\hline Gender & Frequency & $\%$ \\
\hline Male & 29 & 63 \\
Female & 17 & 37 \\
\hline Total & 46 & 100 \\
\hline
\end{tabular}

Table 2 Age Distribution of the Research Subjects

\begin{tabular}{|l|c|}
\hline Age & $\mathbf{n = 4 6}$ \\
\hline Average & 10.35 \\
\hline Standard Deviation (SD) & 4.01 \\
\hline Median & 11 \\
\hline Min-Max & $1-17$ \\
\hline
\end{tabular}

Table 3 Distribution of SCORAD of the Research Subjects

\begin{tabular}{|l|c|}
\hline SCORAD & $\mathbf{n}=\mathbf{4 6}$ \\
\hline Average & 23.15 \\
\hline Standard Deviation (SD) & 9.42 \\
\hline Median & 22 \\
\hline Min-Max & $10.8-59.6$ \\
\hline
\end{tabular}

mild or mild severity ( $\mathrm{n}=33 ; 71.7 \%$ ), followed by moderate $(n=11 ; 23.9 \%)$ and severe $(n=2 ; 4.3 \%)$ (Table 4$)$. Table 5 shows the results of the examination of substance $P$ levels, and the mean value of substance $P$ levels from the 46 patients with $\mathrm{AD}$ was $300.88(\mathrm{SD}=127.55)$, with the lowest level being $172.4 \mathrm{pg} / \mathrm{mL}$ and the highest being $764.4 \mathrm{pg} / \mathrm{mL}$.

The relationship of substance $P$ levels with the degree of AD severity (Figure 1) was analyzed with KruskalWallis test. The results showed that there was no significant relationship between the level of substance $\mathrm{P}$ and the severity of AD (SCORAD category) $(p=0.880)$ (Table 6). Although it did not show a significant relationship, it was seen that subjects with severe AD had the lowest median value of 265.1 (range, 262.8-267.4); it was slightly higher at moderate degree of severity, with a median of 270.21 (range, 177.6-372.7); and mild or mild degree of severity

Table 4 Severity of Atopic Dermatitis (SCORAD Category)

\begin{tabular}{|l|c|c|}
\hline Atopic Dermatitis Severity & Frequency & $\%$ \\
\hline Mild & 33 & 77.1 \\
\hline Moderate & II & 22.9 \\
\hline Severe & 2 & 4.3 \\
\hline Total & 46 & 100 \\
\hline
\end{tabular}

Table 5 Distribution of Substance P Levels in the Subjects

\begin{tabular}{|l|c|}
\hline Level of Substance $\mathbf{P}$ & $\mathbf{n}=\mathbf{4 6}$ \\
\hline Average & 300.88 \\
\hline Standard Deviation & 127.55 \\
\hline (SD) & 270.50 \\
\hline Median & $172.4-764.4$ \\
\hline
\end{tabular}




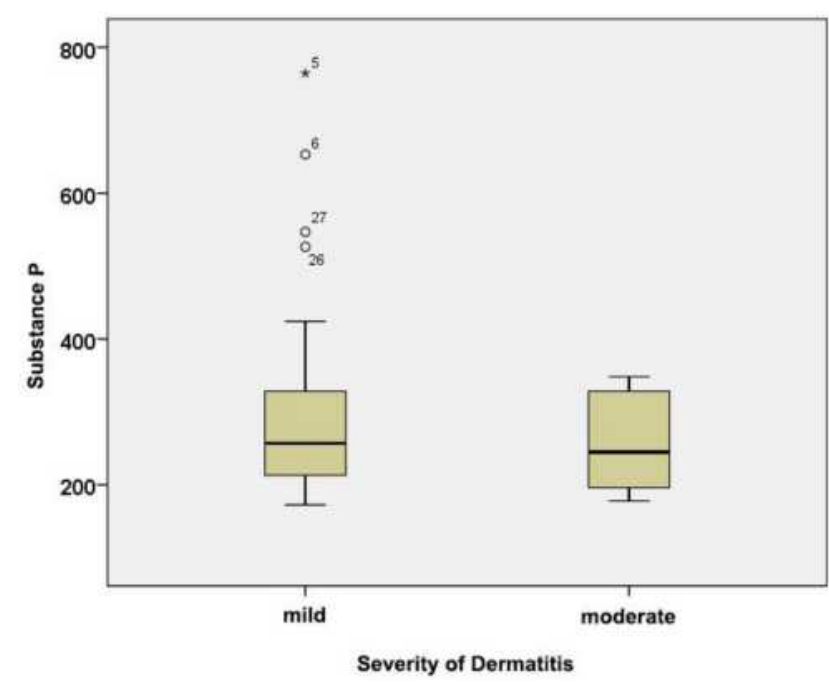

Figure I Boxplot Graph of the Relationship Between Substance P Levels and Degree of AD Severity.

had the highest median value, which was 273.6 (range, 172.4-764.4).

The relationship between substance $\mathrm{P}$ levels and SCORAD (Figure 2) was analyzed using the Spearman correlation. There was no significant correlation between the level of substance $\mathrm{P}$ and the SCORAD value $(\mathrm{p}=$ $0.233 ; \mathrm{r}=-0.179$ ), as shown in Table 7 .

\section{Discussion}

$\mathrm{AD}$ is a major health problem worldwide with prevalence rates of $15-30 \%$ in children and $2-10 \%$ in adults. The ISSAC found that the morbidity rate reached $20 \%$ in Asian countries such as South Korea, Taiwan, and Japan. The AD ratio in women is higher than in men $(1.5: 1)$, and $\mathrm{AD}$ often starts early in the growth period. In children, $45 \%$ of $\mathrm{AD}$ cases first appeared at the age of 6 months, $60 \%$ appeared at the first year of age, and $8 \%$ first appeared before the age of 5 years. ${ }^{9,10}$ In our study, it

Table 6 Relationship Between Substance P Levels and Degree of AD Severity

\begin{tabular}{|l|l|l|l|}
\hline $\begin{array}{l}\text { Atopic Dermatitis } \\
\text { Severity }\end{array}$ & $\mathbf{n}$ & $\begin{array}{l}\text { Substance P, Median } \\
\text { (Range) }\end{array}$ & $\mathbf{p}$ \\
\hline Mild & 33 & $273.6(172.4-764.4)$ & 0.880 \\
\hline Moderate & II & $270.21(177.6-372.7)$ & \\
\hline Severe & 2 & $265.1(262.8-267.4)$ & \\
\hline
\end{tabular}

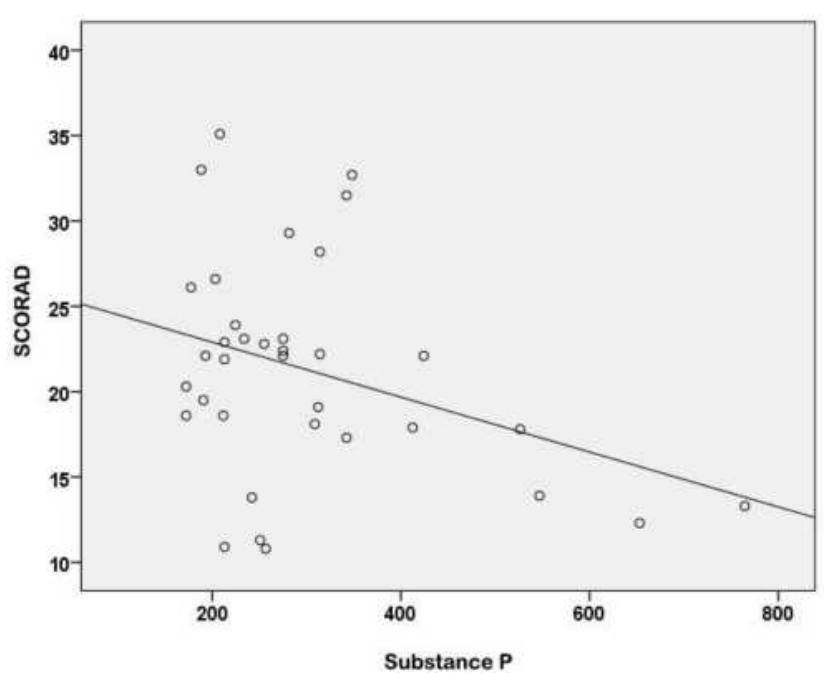

Figure 2 Scatterplot Graph of the Correlation Between Substance P Levels and SCORAD Value.

was found that there was more frequency in males, with an average age of 10 years.

AD severity was assessed using the SCORAD. The SCORAD index was developed by the European Task Force on AD (ETFAD) in 1993 and is one of the most frequently used measures to assess $\mathrm{AD}$ severity. The SCORAD assesses the extent of skin lesions, intensity of the morphology of the lesions, and subjective complaints. ${ }^{11,12}$ In our study, it was found that mild AD is the most common form of $\mathrm{AD}$ in the study subjects.

Several studies support the important role of neuropeptides in the pathophysiology of pruritus in various skin diseases. ${ }^{8}$ MRGPRX2 is the major substance $\mathrm{P}$ receptor on skin mast cells, causing an increased inflammatory response and predisposing AD development. ${ }^{6}$ Substance $\mathrm{P}$ has been postulated to have an important role in AD. ${ }^{5}$ Plasma levels of the neuropeptide substance $\mathrm{P}$ are elevated in patients with $\mathrm{AD}$ and remain elevated even after remission. Increased levels of substance $\mathrm{P}$ in $\mathrm{AD}$ induce the release of IFN$\gamma$, IL-4, TNF- $\alpha$, and IL-10 from peripheral blood mononuclear leukocytes. ${ }^{13}$ However, our study found that

Table 7 Relationship Between Substance P Levels and SCORAD Value

\begin{tabular}{|l|l|l|}
\hline & \multicolumn{2}{|l|}{ SCORAD } \\
\hline & $\boldsymbol{P}$ & $\mathbf{r}$ \\
\hline Substance P & 0.233 & -0.179 \\
\hline
\end{tabular}


there was no relationship between the level of substance $P$ and the severity of AD.

The limitations of this study include a small number of cases, no control group, and we only found two cases of severe AD. To generalize the results, further studies with wide range population and $\mathrm{AD}$ severity might be done in the future.

\section{Conclusion}

Most subjects in AD were male, with a mean age of 10.09 years, the youngest being 1 year old and the oldest being 17 years old. Majority of the subjects had mild AD. In addition, there was no significant relationship between the level of substance $\mathrm{P}$ and the severity of $\mathrm{AD}$, and no significant correlation was found between the level of substance $P$ and the SCORAD value.

\section{Acknowledgment}

Research Foundation of Universitas Sumatera Utara Budget Period of 2020 supported this research with the Letter of Agreement for Research Implementation of the Mono Program for Basic Research in fiscal year 2020 Number 62/UN5.2.3.1/PPM/SPP-TALENTA USU/2020 dated April 28th 2020. We thank our colleagues from Department of Dermatology and Venereology, Faculty of Medicine, Universitas Sumatera Utara, Universitas Sumatera Utara Hospital, and Prodia Laboratory who provided insight and expertise that greatly assisted the research.

\section{Disclosure}

The authors report no conflicts of interest in this work.

\section{References}

1. Simpson EL, Leung DYM, Eichenfield LF, Boguniewicz M. Atopic dermatitis. In: Kang S, Amagai M, Bruckner AL, et al., editors. Fitzpatrick's Dermatology in General Medicine. 9 ed. New York: Mc Graw Hill Inc; 2019:363-381.

2. Lawton S. Atopic eczema in children: nice quality standard. Community Pract. 2013;86(11):46.

3. Siregar RS. Atlas Saripati Penyakit Kulit Dan Kelamin [Atlas of Diseases in Dermatology and Venereology]. 2 ed. Jakarta: EGC; 2005.

4. Leung DYM. New insights into atopic dermatitis: role of skin barrier and immune dysregulation. Allergol Int. 2013;62:151-161. doi:10.2332/allergolint.13-RAI-0564

5. Hosokawa C, Takeuchi S, Furue M. Severity scores, itch scores, and plasma substance $\mathrm{p}$ levels in atopic dermatitis treated with standard topical therapy with oral olopatadine hydrochloride. J Dermatol. 2009;36:185-190. doi:10.1111/j.1346-8138.2009.00621x

6. Babina M, Wang Z. MRGPRX2 signals its importance in cutaneous mast cell biology: does MRGPRX2 connect mast cells and atopic dermatitis? Exp Dermatol. 2020;1-8. doi:10.1111/exd.14182

7. Lotts T, Ständer S. Research in practice: substance $\mathrm{P}$ antagonism in chronic pruritus. J Dtsch Dermatol Ges. 2014;123. doi:10.1111/ ddg. 12364

8. Mehta D, Granstein R. Immunoregulatory effects of neuropeptides on endothelial cells: relevance to dermatological disorders. Dermatology. 2019;235:1-12. doi:10.1159/000496538

9. Munawwarah L, Evalina R, Sofyani S. Serum 25-hydroxyvitamin-D level and atopic dermatitis severity in children. Paediatr Indones. 2017.

10. Umar M, Sastry KS, Ali FA, Wang E, Chouchane AI. Vitamin D and pathophysiology of inflammatory skin disease. Skin Pharmacol Physiol. 2018;31(2):74-86. doi:10.1159/000485132

11. De D, Kanwar AJ. Comparative efficacy of Hanifin and Rajka's criteria and the UK working party's diagnostic criteria in diagnostic of atopic dermatitis in a hospital setting in North India. $J$ Eur Acad Dermatol Venereol. 2006;20:853-928. doi:10.1111/j.14683083.2006.01664.x

12. Patrizi A, Pileri A, Bellini F, et al. Atopic dermatitis and the atopic march: what is new. J Allergy (Cairo). 2011;2011:1-5. doi:10.1155/ 2011/279425

13. Choi JE, Nardo A. Skin neurogenic inflammation. Semin Immunopathol. 2018;40(3):249-259. doi:10.1007/s00281-018-0675-z
Clinical, Cosmetic and Investigational Dermatology

\section{Publish your work in this journal}

Clinical, Cosmetic and Investigational Dermatology is an international, peer-reviewed, open access, online journal that focuses on the latest clinical and experimental research in all aspects of skin disease and cosmetic interventions. This journal is indexed on CAS.
The manuscript management system is completely online and includes a very quick and fair peer-review system, which is all easy to use. Visit http://www.dovepress.com/testimonials.php to read real quotes from published authors. 